\title{
HERMENÉUTICA PRÁCTICA: HABERMAS VS. GADAMER
}

\section{GUILLERMO HOYOS VÁSQUEZ}

Resumen: La ponencia se orienta a mostrar cómo la comunicación en el mundo de la vida requiere, al mismo tiempo, de la comprensión -que sólo puede dar el momento hermenéutico- y de la argumentación -siempre relativa a la capacidad de presentar un fundamento que oriente al consenso-. Parte de una descripción del modo como opera el conflicto de las interpretaciones en el mundo de la vida, tomando como referencia un ejemplo del acontecer colombiano; se intema en las relaciones, oposiciones y complementariedades que se dan entre los puntos de vista de J. Habermas y H-G. Gadamer; concluye examinando los motivos y razones por los que el Estado de Derecho requiere el giro de comprender a argumentar.

Palabras clave: hermenéutica, mundo de la vida, interpretación, fenomenología, argumentación, teoría de la acción comunicativa.

Summary: The lecture aims to show how communication in the world of the life requires, at the same time, understanding -that can only be given by the hermeneutic moment- and argument -always relative to the ability to present a foundation that leads to consent-. It starts by a description of how conflict of interpretations operates in the world of the life. Taking as reference an example from a Colombian daily life affair; it goes into in the relationships, oppositions and complementarities between J. Habemas and H-G. Gadamer points of view. It concludes examining the reasons why the so called State of Rights requires the turn into understanding, into arguing.

Key words: hermeneutics, world of the life, interpretation, phenomenology, argument, Theory of Communicative Action.

\section{El conflicto de las interpretaciones en el mundo de la vida ${ }^{1}$}

La fenomenología está en los orígenes de la hemenéutica, fundamentalmente, en la tradición heideggeriana, pero, ciertamente, también se acerca al tema la pers pectiva desarrollada por E. Husserl ${ }^{3}$.

\footnotetext{
${ }^{1}$ Este texto recoge lo fundamental de la exposición del autor en el Ciclo de Conferencias "Hermenéutica y Ciencias Sociales", basada en un artículo del mismo, en proceso de publicación: "Ética y educación para una ciudadanía democrática" en: Varios Autores, Camino hacia nuevas ciudadanías. Bogotá, PENSAR y Departamento Administrativo de Bienestar Social, 2003; págs. 83-1 14. La transcripción fue realizada por Aracelly Bastidas Orjuela; y revisada por el autor.

${ }^{3}$ Cf. HERRERA RESTREPO, Daniel. Fenomenología y hermenéutica. (1 $1^{\text {a }}$ Conferencia de este mismo ciclo). 
Hablar de hemenéutica obliga a comenzar refiriendo experiencias del mundo vital cotidiano; en este caso, algo que se vivió en la Semana Santa en Colombia, por los medios. Se trata del debate entre el P. Alfonso Llano y Monseñor Pedro Rubiano, que es una cuestión eminentemente hemenéutica.

Monseñor Rubiano argumentó que Jesús es verdadero $\operatorname{Dios}^{4}$ y dijo que así está expresado en las Escrituras tanto como en el dogma cristiano -que no es otra cosa que un esfuerzo de interpretación autorizada canónica de las Escrituras-. Llano $^{5}$, previamente, había indicado que Jesús es verdadero hombre e insistió en que su interpretación parte de la posibilidad del cristiano común y corriente de relacionarse y comprender a Jesús en lo que significa ser hombre auténtico, ser un verdadero hombre, y, en esa medida, de asumirlo como un paradigma.

Se sabe en qué va el debate: hay una interpretación, es decir, hay una hermenéutica; la de Monseñor Rubiano es una hemenéutica canónica. Cuando se estudia teología, se constata que cierto sentido de la hemenéutica tiende a seguir la tradición canónica. El Concilio Vaticano II (1962-1965) empezó a introducir variantes metodológicas en la hemenéutica dentro de la Iglesia Católica. Antes, la hermenéutica era prioritariamente propiedad de la tradición protestante, desde el punto de vista de que ésta pide fundamentar la interpretación.

La tradición protestante busca que la interpretación de teólogos y de predicadores se fundamente desde sí misma; es decir, que se dé valor a la interpretación del mensaje en cuanto interpretación de alguien y para alguien, es decir en cuanto interpretación como tal. La Iglesia Católica en el Concilio Vaticano II asumió algunos de estos principios de la hemenéutica que busca recuperar su propio fundamento. No obstante, todavía sigue habiendo dentro de ella una "doctrina magistral" o "doctrina de Magisterio" que se caracteriza por una interpretación canónica. Ésta es la que se ha sentado en los diversos concilios. Los concilios recomiendan unos postulados doctrinarios; entonces la hemenéutica queda en su momento deteriorada porque pierde su sentido de interpretación; y ésta, a su turno, queda, a veces, relevada por doctrinas, que no son interpretantes. Se comprende, entonces, por qué Monseñor Rubiano le decía al P. Llano « iEsto es lo que hay que creer!».

Ese debate requiere una lectura filosófica. Tal lectura se puede ampliar recurriendo a uno de los filósofos contemporáneos más brillantes -sin que necesariamente se esté de acuerdo con sus tesis-: Alasdair Maclntyre. Él es un filósofo católico, proveniente de una tradición católica. El libro que viene al caso referir es Las tres versiones rivales de la ética ${ }^{6}$, donde se reproduce una serie de conferencias que dictó en su tierra natal, la tierra de sus ancestros. En el

\footnotetext{
${ }^{4}$ LLANO, Alfonso. "Papá: ¿Qué es Semana Santa?” En:El Tiempo. Bogotá, 13 de abril de 2003.

${ }^{5}$ El Tiempo. Sigue tempestad en la Iglesia. Abril 26 de 2003. En: http://eltiempo.terra.com.co/poli/2003-0427/ARTICULO-WEB-NOTA_INTERIOR-1070276.html.

${ }^{6}$ MACINTYRE, Alasdair. Tres versiones rivales de la ética. Enciclopedia, Genealogía y Tradición. Rialp, Madrid, 1996.
} 
trasfondo trae la posibilidad de defender por qué es importante dar conferencias, por qué se requiere la academia, por qué tiene sentido la universidad -que, en fin de cuentas, son procesos hermenéuticos-.

Para Maclntyre las "tres versiones rivales de la ética" equivalen a lo que se expresa con estos subtítulos de su libro: Enciclopedia, Genealogía y Tradición; son tres momentos que tuvieron un significado estelar en la década de los años noventa del siglo XIX, en vís peras del siglo que acaba de terminar.

La Enciclopedia. En 1890, lo recuerda Maclntyre, ve la luz pública la Novena Edición de la Enciclopedia Británica. El sentido de ésta en cuanto hito radica en que presenta el mundo de un modo organizado, con un programa para el ser humano dentro del mundo; en él somos amos y poseedores de la naturaleza, del saber, de la his toria, en cierta forma de nuestro propio proceder; y este saber está programado para que lo único que haya que hacer se limite a realizar lo propues to en el programa de la Modernidad. Ésta, por supuesto, es secular. Para Maclntyre la universidad contemporánea, dentro de este contexto, es nostálgica de la Modernidad sugerida y -hasta cierto punto- sistematizada allí; tal Modernidad es la de la ciencia, la de la técnica, la de la tecnología, la de la "Modemidad ilustrada". La universidad contemporánea es nostálgica de un saber libre de valores, apoyado únicamente en el conocimiento de lo verdadero, lo objetivo, lo preciso, medible y exacto.

Acaso se pueda pensar que las universidades colombianas, o por lo menos algunas de ellas, efectivamente cumplen ese programa de la Enciclopedia; y las que no lo cumplen son consideradas como "todavía no tan buenas"; mientras se juzga que las que llevan a cabo ese programa son "auténticas universidades" y las que no lo alcanzan aún no lo son.

La genealogía. La década de los noventa del siglo XIX tiene, además, otro hito: aparece La genealogía de la moral de F. Nietzsche ${ }^{7}$. Simplificando lo planteado allí, lo que sugiere es todo lo contrario: el programa del hombre moderno, que piensa 'que se las sabe todas', no ha podido reconocer su génesis en un componente como el de la sensibilidad tanto moral como estética; en un componente fuerte de fragmentación, precisamente aquel con el que ese hombre de la Novena Edición de la Enciclopedia Británica está en vísperas de acabar como un superhombre.

Con esta obra, Nietzsche inaugura otra tradición del conocimiento, eminentemente teórica y a la vez práctica, que también resulta ser céntricamente retórica. El modelo de La genealogía, dice Maclntyre, está recogido en una universidad y en un tipo de saber que precisamente no pretende ser canónico, así sean canónicas la ciencia, la técnica y la tecnología. Él ve expresada esa

\footnotetext{
${ }^{7}$ Zur Genealogieder Moral, Eine Streitschrift. Leipzig, Verlag von CG Naumann, 1887. 
universidad en "Mayo del 68" y en los acontecimientos de la Universidad de Nanterre ${ }^{8}$.

La tradición. En la última década del siglo XIX el Papa León XIII publica la Encíclica AEterni Patris ${ }^{9}$ donde dice que las universidades católicas deben volver a Tomás de Aquino, es decir, retomar a 1241. Maclntyre, conocedor de la tradición escolástica, hace ese recorrido en sus conferencias. La última la dedica a la universidad contemporánea. Su tesis es que la gran tragedia de ésta radica en que pretenda ser únicamente la de la Novena Edición de la Enciclopedia Británica; y, por eso, efectivamente, Mayo del 68 significa para tal ideal la hecatombe de las universidades: la revuelta del 68 en Europa y EU, los movimientos del 70 en América Latina.

Una universidad como la de París, donde estuvo Tomás ${ }^{10}$, es mucho menos conservadora de lo que pretende la mentada Encíclica. Maclntyre analiza lo que pasó en París: Tomás hacía, entre otras cosas, las veces de 'puente' entre agustinianos y aristotélicos ${ }^{11}$. "Jesucris to es verdadero hombre», esa es la tesis de los agustinianos, representados por los franciscanos, que afirman la naturaleza humana del Verbo. Los aristotélicos, representados por los dominicos, sostienen que "Jesucristo es verdadero Dios» y esto lo demuestran con recurso a las Sagradas Escrituras.

¿Qué hacía Tomás? Iba donde los agustinianos y les preguntaba qué problemas enfrentaban en la investigación; éstos le contaban, por ejemplo, el problema de poder comprender cómo Jesucristo es verdadero Dios; Tomás llevaba esta cuestión a los aristotélicos, les decía "resuélvanme este problema y yo en compensación les llevo un problema a los del otro lado"; entonces los aristotélicos le resolvían el problema de la divinidad de Cristo y proponían como problema para los agustinianos el de comprender cómo Cristo puede ser verdadero hombre, sobre lo que Tomás ejercía diligentemente como mediador para que los agustinianos lo solucionaran.

Maclntyre expresa que esa Universidad de París de 1241 era dialéctica, era una universidad de analogía. El término analogía refiere que algo es en parte lo mismo y en parte diferente; y la persona Jesucristo de la que están hablando es el mismo y es en parte diferente: para los unos es más Dios y para los otros es más hombre; y es aquí donde es importante el sistema de analogía, de la interpretación analógica. La hermenéutica es racionalidad analógica. Para Maclntyre, Tomás es el verdadero hemeneuta, es el verdadero intérprete, es el verdadero traductor:

\footnotetext{
${ }^{8}$ El comienzo de una época. Internacional Situacionista. http://www.sindominio.net/ash/is 1201.htm.

9 LEÓN XIII. Epístola encíclica Aeterni Patris. Sobre la restauración de la filosofía cristiana, conforme a la Doctrina de Santo Tomás de Aquino. 4 de agosto de 1879. http://www.filos ofia.org/mfa/far879a.htm.

${ }^{10}$ Estudió en París entre 1245-48 y Colonia entre 1249-52. Se licenció en teología en París, en 1256; regresó a Italia donde se dedicó a la enseñanza. El papa Urbano IV le adjudicó la reorganización en Roma de las enseñanzas de los dominicos. Volvió a Paŕs en 1269 para enseñar en su Universidad. Consiguió ser admitido en el plantel de profesores de la Universidad parisina, pese al rechazo suscitado hacia los profesores de las Órdenes mendicantes, junto a San Buenaventura. Regresó a Nápoles en 1273 y murió un año más tarde mientras viajaba para asistir al Concilio de Lyon convocado por Gregorio X.

${ }^{11}$ Con respecto a la polémica referida al comienzo, cabe decir analógicamente que en la Universidad de París estaban tanto Monseñor Rubiano como el P. Llano; Rubiano es aristotélico, Llano es agustiniano, según los enfoques reseñados. 
Tomás le traduce la concepción de Jesús que tienen los agustinianos a los aristotélicos y viceversa. Con esto ya entonces está el reconocimiento de que la filosofía es políglota porque es capaz de comprender y relacionar diversas concepciones de lo mismo ${ }^{12}$.

Para Maclntyre es necesario -en la universidad contemporánea- volver a los tres tipos de universidad. No se trata, por tanto, de consagrar la Universidad de París. Lo que sucedía en 1241 es lo que pone de presente en cierta manera también El nombre de la rosa de Umberto Eco; lo que se narra allí es cómo en ese momento las tesis triunfaban o se derrotaban en los Concilios. Cuando los agustinianos obtenían un Papa, éste inmediatamente citaba a Concilio; en su desarrollo al tiempo consagraba la humanidad de Jesús y condenaba a los oponentes. Eran los tiempos de la Inquisición, o sea cuando la adhesión a las tes is condenadas, a su tumo, significaba condena a muerte. Después ganaban los aristotélicos, los dominicos, el papado; el Papa citaba a Concilio, condenaba a los defensores de la humanidad de Dios Encarnado, verdadero hombre. No era época de regaño cardenalicio, sino del fuego de la Inquisición.

Maclntyre dice que la universidad contemporánea debería tener instituciones modernas, pero también debería tener otras como las del $1968^{13}$, al tiempo que es posible que ella se manifieste en una vertiente genealógica nietzscheana, y que también son necesarias expresiones como la de París 1241, en las que efectivamente se exprese la racionalidad analógica, esa racionalidad dialéctica en el sentido del diálogo. Esto sólo es posible si se aceptan dos cosas:

1. Cualquiera de las posiciones extremas es interpretación, o sea, es un punto de vista, es un lado de la cosa -"Jesucristo verdadero Dios", "Jesucris to verdadero hombre"-; el problema es ver de qué manera dicha apreciación no se quede en sermera interpretación ${ }^{14}$.

2. Tomás opina que es necesario urgir el principio de la analogía: los puntos de vista aparentemente divergentes, ciertamente en parte son diferentes, pero en parte son idénticos. Esa identidad, esa especie de objetividad, es la que Habemas pretende desarrollar superando la mera comprensión que interpreta -

\footnotetext{
${ }^{12}$ Ver HABERMAS, Jürgen. Texte und Kontexte. Frank furt, Suhrkamp, 1991; pág.41.

13 “ Cabe señalar que la Sorbona no es sinónimo de universidad francesa, ni entonces ni ahora: si antes de 1968 existía la Universidad de París o la Universidad de Grenoble, ahora existen las universidades de Pańs I, II,... hasta XIII; las universidades de Grenoble I, II y III, y las de Montpellier con numeración similar, así como varias más en diversas ciudades. Cada una de esas universidades tiende ahora a tomar, además de su respectiva numeración, el nombre de un personaje ilustre de la vida académica, literaria o política de Francia (Pierre et Marie Curie, Stendhal, Pierre Mendés France, etcétera) o a mantener vivos los mitos de manera compartida: Universidad Panthéon-Sorbonne (Pańs I), Universidad París-Sorbonne (P anís IV), Universidad de la Sorbonne-Nouvelle (Pańs III), etcétera".

DE LA VEGA NAVARRO, Ángel. La Universidad francesa después de '68. http://www.jornada.unam. mx/2000/ene00/000116/sem-navarro html.

Esto es lo que le va a criticar Habermas a Gadamer. la crítica de aquél a éste es lo que se va a llamar también un "idealismo hemenéutico", o sea, todo, absolutamente todo, es interpretación.

Cf. Habermas, Jürgen. Der Universalitätsanspruch der Hermeneutik. Im: Hermeneutik und Dialektik. R. Bubner (Hgs.). Tübingen, 1970; II Band, s. 73-104.
} 
sin ignorar, sin tachar y sin negar la hermenéutica- gracias a la teoría del actuar comunicacional.

Entonces, la tesis es la siguiente: es necesaria la hermenéutica, pero la hermenéutica no puede ser canónica, porque entonces deja de ser interpretación, es decir, la hemenéutica no puede acudir a ningún apoyo diferente a la comunicación misma. La interpretación vive de comunicación.

La tesis fundamental es que al afimar la necesidad de la hemenéutica, no se puede caer en una especie de "universalismo idealis ta de la hemenéutica". Esto se puede evitar si se reconocer que la hermenéutica ciertamente es punto de entrada necesario hacia la comprensión, la comunicación y la argumentación, pero que al mismo tiempo la argumentación sigue dependiendo de la comprensión hermenéutica.

\section{El puesto de la hermenéutica en el actuar comunicacional}

Quienes critican cierto 'racionalismo consensual' de Habemas lo hacen con toda razón. En un primer momento de su planteamiento en la Teoría de la acción comunicativa $^{15}$, Habermas sabe que la entrada a la comunicación, al diálogo, es eminentemente retórica; que la comunicación es apertura (eso se diagrama más adelante), pero obsesionado como está con la tradición kantiana, en la que se ha formado, ve la posibilidad de llegar a consensos gracias a la argumentación. Es entonces cuando se entusiasma por las posibilidades del consenso y olvida que más importante que el consenso mismo siguen siendo los disensos, es decir, que aquéllos viven de éstos. Esa va a ser la tesis que va a tratar posteriormente.

\section{Habemas y la hermenéutica gadameriana}

Habermas confronta al menos en tres momentos la hermenéutica de HansGeorg Gadamer. En el primero enfrenta las tesis de La pretensión universalista de la hermenéutica; és te es el título del homenaje que Habermas escribe con ocasión de los 70 años de nacimiento de Gadamer -jhace ya 32 años!- ${ }^{16}$. En el segundo, valora los hitos más relevantes de ésta dentro del pensamiento filosófico de Gadamer, en el homenaje a sus 100 años, mostrando que la hemenéutica gadameriana es filosofía postmetafísica, es postontología; ésta es una filosofía que medra, que vive ampliando las posibilidades de la hemenéutica. En un tercer momento, tras la muerte de Gadamer, en su homenaje, muestra cómo en varias etapas de su propia obra, él halla fundamento en la hemenéutica de Gadamer para el desarrollo de su pensamiento.

\footnotetext{
15 Habermas, Jürgen. Theorie des kommunikativen Handelns: Zur Kritik der funktionalistischen Vernunft. 2 Bde., Frankfurt aM: Suhrkamp, 1981.

${ }^{16}$ En castellano: Habermas, Jürgen. 5. La pretensión de universalidad de la hermenéutica. En: La lógica de las Ciencias Sociales. Madrid, Ed. Tecnos, 1990 (2ª . Edición); págs. 277 a 306. Cf. Hoyos Vásquez, Guillermo - Vargas Guillén, Germán. La teoría de la acción comunicativa como nuevo paradigma de investigación en ciencias sociales: las ciencias de ladiscusión. Bogotá, ICFES, 1997; págs. 191 a 216. 
La hemenéutica está presente en La teoría de la acción comunicativa, en el que podríamos Ilamar 'un segundo Habemas ${ }^{17}$, cuyo pensamiento se consolida en el año de 1981; entonces el actuar comunicacional cobra todo su valor filosófico y comienza a aplicarse a la conciencia moral; dicho planteamiento vuelve a estar presente en Conciencia moral y acción comunicativa en el Capítulo 2 que lleva como título Ciencias sociales reconstructivas vs. comprensivas (verstehende), que son las ciencias del comprender; y, más recientemente, en Verdad y justificación, especialmente en la Introducción y en el primer ensayo desde una perspectiva epistemológica- titulado Filosofía hemenéutica y analítica. Dos clases complementarias del uso del giro lingüístico.

\section{ESTRUCTURAS DE LA COMUNICACIÓN Y DEL MUNDO DE NIVEL 0 : $\quad$ Comprensión \\ Nivel hermenéutico \\ - Apertura \\ -Reconocimiento del otro \\ -Pluralismo}

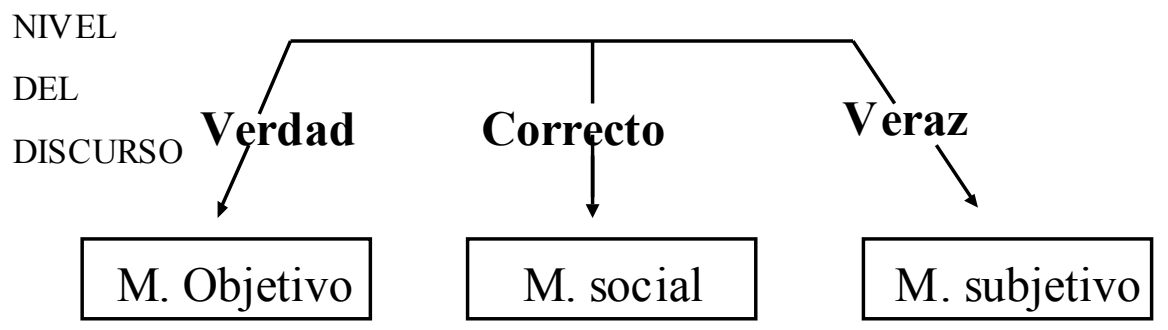

Comunicación, hemenéutica y mundo de la vida

El punto de partida se llama mundo de la vida: es el mundo en el que todos vivimos, en el que todos nos movemos, donde se realizan tanto las operaciones vitales como las cognoscitivas -como parte de aquéllas-. La comunicación en todo momento se refiere al mundo de la vida, aunque, de todas maneras, éste es mucho más amplio que aquélla: el mundo de la vida es mucho más de lo que se puede 'decir' de él.

Por comunicación se entiende la comunicación-lenguaje con actos de habla, naturales dentro de la comunicación cotidiana. Es más amplia que los textos, los monumentos, los símbolos, los bocetos; todos éstos son comunicación; pero

\footnotetext{
${ }^{17}$ El primero podría ser todavía el Homenaje a Gadamer: La pretensión de universalidad de la hermenéutica, Ob. cit. 
cuando se quiere clarificar un gesto que, por ejemplo, resulta ambiguo, se tienen que usar "actos de habla", palabras. Por ejem plo cuando se ve una persona a la que se le encogió la cara, y se piensa que me está haciendo mala cara: la única posibilidad de explicitar la situación es con actos de habla.

\section{La comunicación referida al mundo de la vida}

Se entiende que el mundo de la vida es un recurso fenomenológico; en él estamos todos naturalmente. En fenomenología se piensa que el mundo de la vida es mi correlato, es el correlato de mi conciencia, fuente de mis vivencias, de $m$ is experiencias, de $\mathrm{m}$ is actos intencionales; $y$ en el mundo de la vida hay unos objetos que se mueven, cosas de esas, unas máquinas maravillosas, como decía Descartes $^{18}$; y a esas máquinas maravillosas, desafortunadamente, dentro de la perspectiva fenomenológica les tengo que aplicar el yo-conciencia como si yo estuviera allí (Hua. I, §44) $)^{19}$.

Referido al mundo de la vida la tesis de Habemas ${ }^{20}$ es que el trato lingüístico es lo que media con el mundo de la vida. Éste es, por naturaleza, plural: en él están tanto ustedes, como nosotros, como vosotros, como ellos, como ellas, como yo; están nuestros padres y los que vivirán en los siglos venideros; y todos están en el mismo mundo; cada uno con sus contextos, sus diferencias y sus especificidades.

¿Cómo sabe cada yo de todo eso? Entregándole la palabra al otro para que explique cómo ve el mundo -de la vida, diría Husserl-; cómo lo ve ella, si es mujer, des de su perspectiva. A final Husserl afima que tal experiencia sólo se da al sujeto en forma de como si yo estuviera allá, en su lugar; tal afirmación no puede ser posible, porque, si quiere estar donde ese otro está ahora, tiene que sacar a ese otro de donde está y ya no está como si estuviera allá.

Para Habemas se deriva como consecuencia que la altemativa debe ser que ese otro tome la palabra, que cuente cómo es su experiencia, que manifieste su punto de vista, que explicite su perspectiva. En esto radica la revolucionaria dialógica propuesta en la Teoría de la acción comunicativa.

\footnotetext{
18 “ (...) aunqueyo considero todo esto en mi mismo sin pronunciar palabras, las palabras, sin embargo, me estorban, y me siento casi engañado por los términos del lenguaje ordinario, pues (...) casi concluińa que se conoce (...) por la visión de los ojos, y no únicamente por la inspección del espínitu, si por casual idad no observara desde una ventanalas personas que pasan por la calle, al ver las cuales no dejo de decir que veo hombres (...) y, sin embargo, qué veo desde mi ventana sino sombreros y capas que pueden cubrir espectros u hombres artificiales que no se mueven más que por resortes, pero que yo juzgo que son hombres verdaderos; y de este modo comprendo únicamente por la potencia de juzgar que radica en mi espíritu lo que creía ver con mis ojos" (A.T., IX, 25).

${ }^{19}$ HUSSERL, Edmund. Cartesianische Meditationen. (Hua. I). Dordrecht, Martinus NijhoffPublishers, 1973.

${ }^{20}$ Para Habermas, en los inicios de la teońa comunicacional, la racionalidad comunicativa es un plexo de pretensiones de validez con cuatro clases de pretensiones, que son cooriginarias: inteligibilidad, verdad, rectitud y veracidad, constituyen un plexo al que podemos llamar racionalidad (HABERMAS, Jürgen. El discurso filosófico de la Modernidad. Madrid, Ed. Taurus, 1989; pág. 121).
} 
El cambio de paradigma de la filosofía de la conciencia (Husserl) a una acción, a un actuar comunicativo (Habermas) privilegia el lenguaje como punto de partida; tal lenguaje está referido en todo momento y actividad al mundo de la vida. Entonces se va a hablar del lenguaje, de la comunicación, en dos niveles:

Nivel cero de la comunicación. Es en él donde está la hemenéutica. Se lo puede llamar, por igual, el nivel hemenéutico de la comunicación: hay situaciones del mundo de la vida que, para comprenderlas plenamente, se requiere, en primer lugar, diferenciarlas mediante la utilización de un lenguaje llano y directo.

Nivel uno de la comunicación. Éste es el nivel discursivo-argumentativo. La gente común y corriente siempre puede decir que el sol sale por el Oriente, pero en el momento en el que se requiere consolidar un poco más un conocimiento es necesario dar el paso a la argumentación; ahí la comunicación no es sólo para describir ese primer ámbito, el de la comprensión, sino que la comunicación argumenta y discurre para dar fundamento ${ }^{21}$ a afirmaciones que requieren ser demostradas porque pretenden ser objetivas.

Es preciso observar -para hacer más comprensible la propues ta de Habemasque los dos niveles de comunicación (0/1) se necesitan mutuamente, aunque son diferentes. Mi interpretación es que el universalismo de la hemenéutica ha Ilevado a Gadamer a quedarse en el nivel 0; a su vez, desde el nivel 0, Gadamer puede reclamarle a Habermas que no sólo pase por la mediación hemenéutica, sino que se conserve en ella. Habemas, en cambio, en su primera etapa al descubrir el giro lingüístico, da la impresión de que al encontrar las posibilidades argumentativas del discurso comunicativo 'vota la escalera' y piensa que no necesita más de la hermenéutica. Como consecuencia se produce también en su teoría un cierto idealismo, -ya no el idealismo hermenéutico- sino su contraparte, a saber, un racionalismo consensual habemasiano; en éste el actuar comunicacional parece ocuparse exclusivamente de los consensos, olvidando que éstos viven de los disensos, de las diferencias.

Habermas va a superar gradualmente esta unilateralidad que invalida en cierta forma su propuesta. Para ello es necesario encontrar la complementariedad entre estas dos dimensiones de la acción comunicativa: el uso comprensivo del lenguaje

\footnotetext{
${ }^{21}$ Esto sucede de la misma manera como se han separado los tres tipos de: 1. Discursos teóricos con respecto a una región objetiva del mundo de la vida, el mundo objetivo de las ciencias 'duras' como la física, la química, la matemática, la biología; éstas son las ciencias que cuentan con datos, con hechos empíricos, y llegan a ellos argumentando y dando razones, etc. 2. Hay otra región del mundo de la vida que es mundo social, que es un poco más complejo, más flexible, mucho más dependiente de la comprensión. A esta región del mundo de la vida corresponden las ciencias 'blandas', como la pedagogía, la sociología, la antropología, la ciencia politica. De hecho están también la ética y muchos aspectos relacionados con la moral. 3. Hay, finalmente, otro tipo de discursos que son los que provienen de la región del mundo de la vida personal, del mundo subjetivo, el cual deviene como la dimensión de la retórica; es el campo de la dramaturgia, de la escénica, del psicoanálisis, de la subjetividad que se expresa enfáticamente como mi comunicación.

Con respecto al gráfico, se refieren estos tres tipos de discurso a la parte de la base, de la comunicación como discurso.
} 
(Nivel 0) yel uso argumentativo (Nivel 1), para es tablecer cómo se compenetran y complementan, sin que sean reducidos a lo mismo ${ }^{22}$.

El cambio de paradigma es una respuesta práctica de la filosofía a lo que efectivamente ésta puede hacer, que es intercambiar mundos de vida. ¿Cómo se logra tal intercambio?, ¿cómo se pueden cruzar los mundos de vida?, ¿cómo se va estableciendo una red de mundos de vida? La respuesta es: gracias a la comunicación, no en el sentido de las determinaciones de las instancias administrativas que emiten prescripciones; sino en el de lo que sucede en los procesos comprensivos y deliberativos que anteceden a todo acuerdo. Esa es la comunicación de la que parte la Teoría del actuar comunicacional, dando con ello toda la razón a la tesis de que es posible hacer todas las cosas con palabras, inclusive aquellos que nos hemos acostumbrado a hacer violentamente.

La hemenéutica tiene una estructura comunicacional eminentemente comprensiva -en la tradición del neokantismo se llama comprensión de sentido $(\text { Sinnverstehen })^{23}$. El lenguaje en la fenomenología está vivo pero se queda, por así decirlo, a mitad de camino; entonces, lo que hay que ver es cómo se constituye la interpretación en los procesos comunicativos en el mundo de la vida, en la cotidianidad, donde se abren las perspectivas de los participantes; es decir, en la com unicación cada quien da su punto de vista, su perspectiva: del mundo de la vida sólo se pueden tener perspectivas, porque és te es contexto para todos, es conjunto de tradiciones, de virtudes, de convicciones, de percepciones. En consecuencia, en la comunicación lo único que puede decir cada quien es cómo ve des de su lugar y cómo des de allí se le da, se le abre el mundo. No se debe ni se puede olvidar el sentido fundamental de "el mundo como tema de la fenomenología"24.

Para Huss erl, el horizonte de horizontes es algo que comienza en la subjetividad y se va abriendo, y dentro de ese horizonte el sujeto se encuentra con los otros. Sin embargo, este planteamiento no es del todo aceptable, pues el horizonte es, en principio, absolutamente plural y se constituye por diferencias, no por la intencionalidad de una conciencia monológica. Precisamente esta deficiencia de la fenomenología hace de la comunicación el método originario para acceder al mundo plural: es la comunicación la que abre las múltiples perspectivas del mundo al dar cada quien su pers pectiva y disponiendo a todos para recibir otras versiones

\footnotetext{
${ }^{22}$ Para ello es preciso revisar los orígenes de la comunicación y tomar distancia de Husserl, pues para él el lenguaje es monológico, o sea, no es lenguaje. Hussenl habla del diálogo del alma consigo misma ${ }^{22}$, y eso no es diálogo, es monólogo. En ese punto tiene validez la crítica de Foucault a la tradición de la "filosofia de la conciencia"-todavía la fenomenología lo es-, pues ella tiene como ideales el autoconocimiento, la autorreflexión y la autodeterminación; ella explica el conocimiento desde la autoconstitución. La crítica foucaultiana muestra que así se desemboca en un autismo, y eso obliga a criticar el monólogo como en cierta forma 'enfermizo'.

${ }^{23}$ La fenomenología sostiene que la subjetividad constituye el sentido y que la función del lenguaje consiste en expresarlo; que el yo lo constituye en la conciencia. El lenguaje, en fenomenología, es un mero instrumento de expresión. Eso, en la perspectiva hermenéutica, es empobrecer el lenguaje.

${ }^{24}$ Ver mis trabajos "El mundo como tema de laf enomenología". En: Humanidades. Revista de la Universidad Industrial de Santander -UIS-. Vol. 22, No. 1, Bucaramanga, Junio 1993; págs. 13-22 y "El mundo de la vida como tema de la fenomenología". En: Universitas Philosophica. Año 10, No. 20, Universidad Javeriana, Bogotá, junio 1993; págs. 137-147.
} 
de lo mismo. El punto de partida hemenéutico de la comunicación, entonces, es la apertura, es la comprensión, en un sentido pleno en el que comprender no me obliga a estar de acuerdo con el otro. Todavía más: para poder estar en acuerdo o en desacuerdo con el otro, debo comprenderlo primero. Ahí mismo es donde se encuentra uno se los puntos más críticos del todo el desarrollo de la hemenéutica y una de sus fortalezas mayores ${ }^{25}$.

La hermenéutica privilegia los textos clásicos, pues éstos gozan de cierta dignidad canónica en la tradición del humanismo tanto cristiano como especialmente clásico. Este privilegio que le da Gadamer es lo que, dice Habemas, le imprime a la hermenéutica gadameriana el riesgo de tornarse dogmática, canónica, pues, adquiere dentro de ella más peso la tradición que la contemporaneidad. En contraposición, Habemas pretende reconocer la tradición en cuanto se des pliegue en un horizonte de futuro abierto -no en una subjetividad trascendental, sino en un futuro abierto para un auditorio universal-. Esa apertura se da con base en el reconocimiento del otro (iy de la otra!) como diferente y en su diferencia, es decir, como interlocutor válido. La comunicación en el nivel hemenéutico (Nivel 0) es el 'reino de las diferencias'; en esa interpretación de la hermenéutica, la comunicación es la que reconoce el punto de partida de lo intersubjetivo, de lo intercultural, de lo pluralista.

El punto crítico está, pues, en que la comunicación se quede en el nivel de las puras interpretaciones, que se privilegie en extremo la necesidad de las diferencias, que se canonice un tipo de interpretaciones y se abandone la cosa misma de la hermenéutica: su naturaleza interpretativa. La hermenéutica pervive en el repaso constante del mismo punto de vis ta con nueva interpretación, ella es un ejercicio como el de los poetas ${ }^{26}$ quienes continuamente recrean, reinventan, un mundo nuevo. El principio radical de la hermenéutica es la interpretación; pero el relativismo absoluto al que tienden las interpretaciones no establece ningún criterio de unidad, sino que privilegia la diversidad, las diferencias. En el nivel fundamental de la hemenéutica comprensiva de la interpretación no se urge siquiera un sentido de veracidad. Si todo es interpretación nos encontramos en determinados casos ante algunas situaciones que producen vértigo.

Alejándose del universalismo propio de la filosofía, la hermenéutica amenaza con terminar en la solución opuesta: 'todo vale'. Ahí es necesario superar la pretensión universalista de la hemenéutica propuesta. La discusión se centra en el contextualismo: si el contexto detemina lo objetivo, el opuesto sería que lo objetivo anula los contextos, lo cual resulta inadmisible. Se tiene que pensar, por

\footnotetext{
${ }^{25}$ En el caso del debate Rubiano-Llano, que se mencionaba al comienzo, se puede decir que hay un punto de vista sobre Jesucristo que es el de la Iglesia dogmática; $y$, por otro lado, se ve a Jesucristo como humano. En el caso de las universidades - que también se trataba atrás-, se puede afirmar, con Maclntyre, que el único canon de universidad no es el que proponía la Novena Edición de la Enciclopedia Británica, y no se puede decir que la única manera de conocer el mundo es la de la Modernidad, y menos aun la de la modernización con base en la ciencia, la técnica y la tecnología-.

${ }^{26}$ RORTY, Richard. Ironía, contingencia y solidaridad. Barcelona, Ed.Paidós, 1991; pág. 112. 
tanto, en cómo conciliar el Nivel 1 -el argumentativo- con el Nivel 0 -el hermenéutico-.

Habemas sostiene que la naturaleza no es cultura esto está en toda la tradición fenomenológica, inclusive en la misma tradición filosófica-, y que, sin embargo, la naturaleza sólo se puede dar culturalmente al sujeto. Esto en términos de la tradición de los griegos significa que el mundo está más allá o más acá de todas las visiones del mundo que se puedan tener de él. En el sentido de Heráclito, al caracterizar al filósofo como el uno de los muchos, sin pretender que es el único, se está expresando que el filósofo sí es el único que sabe que la verdad es síntesis de perspectivas y que las perspectivas son de los muchos y que las perspectivas son diferentes ${ }^{27}$. La Teoría del actuar comunicacional insiste en que este proceso se instaura com unicando, discutiendo, argumentando, apostándole a los mejores argumentos.

Los científicos de la naturaleza ejercen un actuar comunicativo referido a una región objetiva del mundo de la vida. Dicho actuar está mediado por una teoría epistemológica -considérese, por ejemplo, la idea regulatriz kantiana-, que, al tiempo, admite el acercamiento al fenómeno desde diversas perspectivas de lo mismo. Éstas pueden ser las diferentes maneras como se da, por ejemplo, el fenómeno de la rotación de la tierra o el de la caída de los cuerpos en el vacío, etc. Desde diversos puntos de vista, desde diversos fenómenos, se pueden dar explicaciones, argumentos, entre los cuales se apuesta por los mejores, o sea, se prefieren y aceptan los argumentos que puedan llegar a aclarar, a explicar más adecuada y coherentemente; en fin, se prefieren los más completos.

En principio, lo mismo se puede aplicar al mundo social: la Constitución Política o el contrato social que se ha deteminado en una Nación, si se le apuesta a la argumentación y no a la violencia, se fundan en los mejores argumentos desde el punto de la rectitud, la legitimidad, la justificación.

Otro aspecto importante de la comunicación es el que tiene que ver con la credibilidad y la autenticidad de las personas. Este aspecto se relaciona con la subjetividad de cada uno de los participantes. Son las personas, efectivamente, las que, en un mundo de comprensión de los demás, tratan de hacerse creíbles en el sentido de que van habituando a sus oyentes a admitir que lo que dicen está conforme con lo que quieren expresar y comunicar, o sea, que son veraces.

\footnotetext{
${ }^{27}$ Esto lo exponen Heidegger y Husserl cuando explican qué sucede en el mundo antiguo en el que, por ejemplo, las tempestades del mar se llaman de una manera en pentagrama egipcio, de otra manera en pentagrama sirio, de otra manera en pentagrama macedonio y de otra manera en pentagrama griego; pero la tempestad es la misma. Esto es lo que quiere decir Husserl en el pasaje de la Conferencia de Viena, cuando describe la actitud filosófica, en la cual "el hombre contempla ante todo la diversidad de las naciones, las propias y las ajenas, cada una con su mundo circundante propio, considerado con sus tradiciones, sus dioses, demonios, potencias míticas, como el mundo absolutamente evidente y real. Surge, en este sorprendente contraste, la dif erencia entre la representación del mundo y el mundo real y emerge la nueva pregunta por la verdad; por consiguiente no por la verdad cotidiana, vinculada a la tradición, sino por una verdad unitaria, universalmente válida para todos los que no estén deslumbrados por la tradición, una verdad en si" (HUSSERL, Edmund. "La filos ofía en la crisis de la humanidad europea". En: La filosofía como ciencia estricta, Buenos Aires, Nova, 1981; pág. 155).
} 
¿Cómo se llega allá? En términos hemenéuticos: por medio de la comprensión. Comprender la opinión del otro no obliga a estar de acuerdo con él, como ya lo indicamos; aquí no rige el 'todo vale'; en cambio sí es apertura a otros puntos de vista, otras culturas, otras épocas históricas. La apertura, no obstante, no logra solucionar el conflicto, pues el mundo de la vida supera todas las posibilidades de comprenderlo, y se requiere seguir avanzando en la comunicación para llegar, gracias a ella, a puntos de vis ta concordantes que deberían ser mínimos.

Las ciencias 'duras' dan en ello notable ejemplo. Normalmente a éstas se les critica, así como también a la técnica y la tecnología, porque destruyen el medio ambiente, porque ayudan a preparar todos los dispositivos -tanto tecnológicos como económicos- para la guerra; sin embargo, ellas enseñan que, al margen de todas las interpretaciones -de toda hemenéutica- es posible llegar a unos puntos de vista comunes basados en los datos de la naturaleza. La perversión consiste en convertir ese estilo de argumentación en modelo universal y único; esto es lo que se identifica con el positivismo científico que tiene incidencia nefasta en las ciencias sociales, en especial en ciertas orientaciones del comportamiento humano, que se conocen bajo el título, desde el punto de vista del mundo subjetivo, de conductismo.

La racionalidad analógica propuesta por Maclntyre permite ver que las ciencias sociales tienen conflictos, los cuales, por más que se comprendan, no se solucionan con base únicamente en la interpretación-comprensión; también se pueden solucionar o con 'guerra fría' -por poner el caso del conflicto entre Llano y Rubiano-, o con violencia -como ocurre en muchos cas os en Colombia-.

Una interpretación utilizada discursivamente, con las condiciones para la comprensión, conduce al supuesto de que la sola comprensión no alcanza para solucionar el conflicto, que es más complejo que las posibilidades de ésta. Tal fue el descubrimiento de la Modernidad: el contrato social posibilita acordar unos mínimos argumentativa, discursiva, dialogalmente; as í los ciudadanos constituyen el Estado de Derecho y mediante él establecen derechos que pretenden ser los mismos para todos, sin que se desconozcan las diferencias de cada ciudadano particular, es decir, mantienen la diversidad.

El Estado de Derecho moderno es el invento humano -cuando se fueron los dioses y demonios y con ellos la metafísica- de la posibilidad de llegar a unos acuerdos mínimos que fueran la garantía para seguir siendo diferentes en todo lo demás. La argumentación en ciencias sociales no se propone la verdad, pues no hay ninguna verdad absoluta en el ámbito de lo sociocultural; por ello el discurso en ellas configura un tipo de argumentación análogo al de las ciencias empírico analíticas, orientado a elaborar unas reglas de convivencias y una constitución 
correctas, cuya garantía de corrección consiste en los acuerdos sobre mínimos y en el reconocimiento de todas las diferencias ${ }^{28}$.

Los acuerdos en el ámbito social y político, los que dan origen a las Cons tituciones de los pueblos se consiguen argumentando. Por eso, la necesidad de superar la hermenéutica, sin abandonarla, viene de dos razones fundamentales: en primer lugar, se pone en evidencia que el conflicto no se soluciona sólo comprensivamente, como quisiera sugerirlo la hermenéutica. La historia enseña que hay conflictos que son más radicales que la posibilidad de comprenderlos y que, por tanto, es necesario el contrato social que se da como fruto de la actividad comunicativa.

En segundo lugar, el bien común no se obtiene sólo con imaginarios sobre él, sino que, para que éste se concierte y comience a ser realidad, se requieren unos acuerdos mínimos, políticos, éticos, procedimentales, que respeten las diversas concepciones que se presentan necesariamente en su práctica. El bien común no es la concepción particular que de él tiene algún sector de la ciudadanía, sino que es la del común, y a lo común se llega oyendo la diversidad y configurando una idea de bien común, en el que cada quien tenga la posibilidad de realizar su propia perspectiva de bien sin lesionar a otro. Por eso es necesario el Estado de Derecho democrático y participativo.

\section{Hermenéutica práctica}

Para finalizar, es relevante analizar el siguiente pasaje, donde Habermas, después de recibir la propuesta de Gadamer, trata de diferenciarse de él, es decir, de criticarle la pretensión universalista de la hemenéutica. Gadamer le señaló a Habemas que no se confiara exclusivamente en la comunicación argumentativa, pues no hay posibilidad de argumentar si no es a partir de la comprensión hermenéutica previa ${ }^{29}$.

Veamos pues el texto de Habermas:

La contribución metodológica de la hemenéutica filosófica podemos resumirla en los siguientes puntos:

el intérprete no puede esclarecer el significado de una manifestación simbólica sino como participante virtual en el proceso de entendimiento de los directamente implicados;

\footnotetext{
${ }^{28}$ Un caso evidente es la propuesta del subcomandante Marcos: luchar por un México, no para un grupo de personas, no para los zapatistas, sino para zapatistas y no zapatistas, para todos los que quepan en el mismo proyecto libertario (Ver: Periódico El Espectador. Bogotá, 5 de enero de 1997; págs. 10y 11A).

${ }^{29}$ Esto es lo que puede estar pasando en el debate entre Llano-Rubiano: que están argumentando antes de comprender cada quien lo que está comprendiendo el otro -no actúan como Tomás de Aquino-.
} 
esta actitud realizativa ${ }^{30}$ le vincula a la precomprensión que caracteriza a la situación hermenéutica de la que parte;

pero la validez de su interpretación no tiene por qué verse menguada por esa vinculación,

ya que puede servirse de la estructura racional interna de la acción orientada al entendimiento y hacer un uso reflexivo de la competencia de juicio que caracteriza a un participante en la comunicación que sea capaz de responder de sus actos, para

poner sistemáticamente en relación el mundo de la vida del autor y de sus contem poráneos con su propio mundo de la vida

y reconstruir el significado del interpretandum como contenido objetivo de una emisión o manifestación susceptible de crítica, que es sometida a un enjuiciamiento por lo menos implícito ${ }^{31}$.

Habemas, en este texto, reconoce que hay contribución de la hermenéutica en la metodología; para él -en este momento- la hemenéutica está en paralelo con la teoría, con la práctica y con la retórica. En todo caso, lo que se señala es que, por un lado, la hermenéutica es punto de entrada a la comunicación dado que no se puede argumentar si previamente no se comprende, y que tampoco se puede argumentar abandonando las posibilidades de comprensión que ofrece la hermenéutica; y, por otro lado, que lo más importante cuando se llega a los mínimos consensuales son los disensos que quedan, pues de ellos es de lo que sigue hablando toda comunicación subsiguiente.

El concepto contribución metodológica en la teoría de la acción comunicativa se distancia del supuesto de que el principio metodológico fundamental en las ciencias sociales y humanas es la abstención valorativa; según este principio, el investigador debería separarse y distanciarse de los estados de cosas, de las situaciones, no comprometerse con ellas, para poder observarlas objetivamente. Es ta teoría lleva a un callejón sin salida epistemológico en las ciencias sociales: el investigador social, al tiempo que forma parte del universo que pretende investigar, debe tomarlo objetivamente para realizar sus estudios. Ante tal dilema en ciencias sociales se concluye que se debe hacer del mayor obstáculo epistemológico la mayor virtud de la metodología de la investigación; es decir, el investigador social no debe salirse del contexto, del problema y, por el contrario, inmiscuirse en el as unto, pues la objetividad en la teoría de la acción comunicativa no la garantiza la actitud del observador; ella es la resultante del acuerdo discursivo, argumentativo, de todos los participantes. La objetividad está garantizada por los mejores argumentos, los que probablemente son los más comprometidos; la objetividad es el resultado de la dialéctica no su punto de partida.

\footnotetext{
${ }^{30}$ El traductor al español Manuel Jiménez traduce "realizativa". Se podría decir, tal vez más apropiadamente, performativa(-realizativa), es decir, la actitud es realizativa cuando un participante virtual ef ectúa, lleva a cabo una obra o una acción con consecuencias. En este sentido se trata de una actitud performativa.

${ }^{31}$ HABERMAS, Jürgen. Teoría de la acción comunicativa. Madrid, Ed. Taurus, 1989; tomo I, p. 188. 
En consecuencia, el intérprete, el hemeneuta, no puede esclarecer el significado de una manifestación simbólica si la toma des de lo 'apariencial', sino que debe ser un participante eventual en el proceso de entendimiento de los directamente implicados. En la caracterización de la hemenéutica, el intérprete se hace participante de lo que está estudiando y sólo puede comprender participando, no sólo observando.

Gadamer descubrió que la hermenéutica es viva, no es un método, sino el fundamento para encontrar la verdad en la comprensión de sentido, el cual se da en la participación del asunto que se está investigando. Con la observación lo único que se obtienen son datos de cantidad y de causalidad. La validez de la interpretación inmiscuida en la participación no se ve menguada por dicha vinculación, por el contrario, mientras mayor sea el compromiso con el asunto mejor es la interpretación, puesto que, en la comunicación con el otro, el investigador oye las perspectivas del otro, no las presupone, sino que las reconoce con su contenido de validez. Esta es la razón por la cual la hermenéutica no puede servirse exclusivamente de una estructura racional.

La hermenéutica debe servirse de la es tructura racional intema con el propósito de orientar la acción del entendimiento. Con este presupuesto se aclara la posibilidad de dar sentido a las otras perspectivas de lo mismo, de entender los puntos de vista de los otros participantes y no sólo comprenderlos, para que, una vez comprendidos, se pueda controlar si lo que están diciendo los diversos interlocutores es lo mismo de lo mismo.

El investigador hermeneuta puede servirse de la estructura razonable interna de la acción orientada al entendimiento y hacer un uso reflexivo de la competencia de juicio que caracteriza a un participante en la comunicación, que sea capaz de responder por sus actos y que sea capaz de responder por lo que dicen; y no es simplemente emitir un juicio de valor personalizado. Así, en la comunicación se intercambian argumentos y razones del tal modo que el escucha puede considerar la perspectiva del otro y entender el porqué de ese tipo de razones, para que, consiguientemente, el que las escucha pueda compararlas con las propias y ponerlas en consideración también de los demás.

La teoría de la acción comunicativa habermasiana es eminentemente política, es debate y uso reflexivo de la competencia del juicio, que caracteriza a un participante en la comunicación como capaz de responder por sus actos. La manera de ir organizando sistemáticamente el punto de vista del otro, de la historia, del próximo siglo, etc., es referirlos al mundo de la vida abriéndolos comunicativamente.

El caso de los Derechos Humanos es ejemplar. Ahora no se habla de un derecho natural o de una metafísica para fundamentarlos. Cuando se tematizan los derechos humanos se opera con un discurso incluyente: son para todos $y$, en consecuencia, dicho discurso efectivamente asume la diferencia, es decir, 
fundamentalmente se considera y exige el derecho a la diferencia ${ }^{32}$; es por ello que este tipo de juicios práctico-morales no se cierran ni excluyen, y, por el contrario, se abren al apriorismo kantiano de la pregunta: "¿qué puedo conocer?». A esta cuestión cabe responder que todos los humanos son iguales, independientemente de religión, raza, pertenencia, límites geográficos, etc. ${ }^{33}$ y que, sin embargo, deben persistir las diferencias. Se trata de entenderse a partir de ellas, de la hemenéutica; porque ésta ha asimilado la multiplicidad de perspectivas, el caos en el mejor sentido. Lejos de tener nostalgia de unidad y de orden, se trata de construir sistemáticamente unos mínimos, de suerte que siga perviviendo la multiplicidad de lo diverso.

Poner sistemáticamente en relación el mundo de la vida del autor y de sus contemporáneos con el del investigador es reconstruir el significado de lo que se pretende interpretar como contenido objetivo de una emisión o manifestación susceptible de crítica, que es sometida a un enjuiciamiento -al menos implícito-. El aporte de la hemenéutica es la apertura a la multiplicidad del universo. Sin embargo, su trampa se cifra en sus pretensiones universalistas, en considerar que, independientemente de la multiplicidad de lo diverso, no es posible llegar a ningún punto de vista común.

Una teoría de la argumentación, por el contrario, tiene el peligro de pensar que los valores teminan allí donde comienza la razón. El reto está en continuar en los linderos de la hemenéutica, es decir, en la multiplicidad de lo diverso - de los valores-, y, al tiempo, saber que es posible, y algunas veces absolutamente necesario, argumentar.

Habermas lo propone -en el texto comentado- en términos de criticabilidad. Ésta es una es pecie de actitud contrafáctica, en el sentido popperiano ${ }^{34}$ de objetividad basada en la fasabilidad. Esto permite además caracterizar la objetividad como

\footnotetext{
${ }^{32}$ LYOTARD, Jean-François. “Los derechos del otro”. En: Integración, ciencia y tecnología. Bogotá, COLCIENCIAS, Vol., Nº 1, 1994; págs. 97-102

${ }^{33}$ En Foro Extremeño (Culturaextremadura. 99) se indicó: “el foro tiene una importante tarea, la de hacer comprender a las sociedades que los derechos de las mujeres también son derechos humanos, y el respeto a los mismos implica que la sociedad dedique sus mejores esfuerzos a facilitar y mejorar las condiciones para la plena participación de las mujeres en el desarrollo, y a promover la igualdad entre hombres y mujeres, en definitiva a combatir todas las formas de discriminación que se ciernen sobre las mujeres" (subrayado ajeno al texto). Cf. http:/www.juntaex.es/aulturaex/forocontralaviolencia/forocontralaviolencia3.htm Esta misma observación ha sido recogida recientemente en un evento sobre "Derechos en perpectiva de género" por la Procuraduría General de la Nación en Colombia.
}

\footnotetext{
${ }^{34}$ Popper apelaba a una verdad objetiva regulada por la “criticabilidad": es más verdad cuanto más se somete a la crítica o, concretamente, a la falsabilidad.

Cf. POPPER, Kanl. La lógica de la investigación científica. Madrid, Editorial Tecnos, 1977; pág. $240 . \quad$ Objetive Knowledge. An evolutionary approach. Oxford, Clarenton Press, 1979; pág. 156.
} 
posibilidad de aprender. En esta posibilidad se encuentra el valor de cierto pragmatismo de la actividad comunicacional que cuenta con la otras perspectivas y con los puntos de vista de los otros: se basa, en consecuencia, en un principio hermenéutico.

La posibilidad de aprender partiendo de lo otro radica en el poder llegar a hacer propio, hasta donde sea posible, lo que puede haber de lo otro como diferente de lo mío y en lo otro como posiblemente análogamente cercano a lo mío. La educación y la pedagogía, tomadas como espacio de la comunicación, como procedimiento para acercarse a la 'objetividad' del mundo, como competencia de seguir aprendiendo, permiten relacionar el pragmatismo de Dewey, con el evolucionismo de Darwin, con las ideas regulativas de Kant, si se toma como punto de partida y como acompañante la radicalización de la hemenéutica.

\section{BIBLIOGRAFÍA}

APEL, Karl Otto, CORTINA, Adela y OTROS (Eds.). Ética comunicativa y democracia. Barcelona, Ed. Crítica, 1990.

CORTINA, Adela. Ética aplicada y democracia radical. Madrid, Ed. Tecnos, 1993.

DE LA VEGA NAVARRO, Ángel. (SF) La Universidad francesa después de '68. http://www.jornada.unam.mx/2000/ene00/000116/sem-navarro.html.

DESCARTES, René. "Meditaciones metafísicas". En: Obras escogidas. Buenos Aires, Ed. Charcas, 1989.

El comienzo de una época. (SF) Internacional Situacionista. http://www.sindominio.net/ash/is 1201.htm.

El Tiempo. "Sigue tempestad en la Iglesia". 26 de Abril de 2003. En: http://eltiempo.terra.com.co/poli/2003-04-27/ARTICULO-WEB-NOTA INTERIOR1070276.html.

Foro

Extremeño.

(Culturalextremadura.99). http://www.juntaex.es/culturaex/forocontralaviolencia/forocontralaviolencia3.htm.

HABERMAS, Jürgen. "Conocimiento e interés". En: Ideas y Valores. Bogotá, Universidad Nacional de Colombia. (42-45) 73-75; págs. 61-76.

HABERMAS, Jürgen. Conocimiento e interés. Madrid, Ed. Taunus, 1982.

HABERMAS, Jürgen. Conciencia moral y acción comunicativa. Barcelona, Ed. Península, 1985.

HABERMAS, Jürgen. Teoría de la acción comunicativa. Madrid, Ed. Taurus, 1988; 2 vols. 
HABERMAS, Jürgen. "La pretensión de universalidad de la hermenéutica". En: La lógica de las Ciencias Sociales. $2^{\mathrm{a}}$ ed. Madrid, Ed. Tecnos, 1990; págs. 277306.

HABERMAS, Jürgen. El discurso filosófico de la Modernidad. Madrid, Ed. Taurus, 1989.

HABERMAS, Jürgen. Escritos sobre moralidad y eticidad. Barcelona, Ed. Paidos, 1992.

HABERMAS, Jürgen. Facticidad y validez. Sobre el derecho y el Estado democrático de derecho en términos de teoría del discurso. Madrid, Ed. Trotta, 1998.

HERRERA RESTREPO, Daniel. Fenomenología y hermenéutica. (1 a $^{\text {a }}$ Conferencia del ciclo Hermenéutica en ciencias sociales). Bogotá, Universidad Pedagógica Nacional. 2003.

HOYOS VÁSQUEZ, Guillermo \& VARGAS GUILLÉN, Germán. La teoría de la acción comunicativa como nuevo paradigma de investigación en ciencias sociales: las ciencias de la discusión. Bogotá, ICFES, 1997; págs. 191-216.

HOYOS VÁSQUEZ, Guillermo. Los intereses de la vida cotidiana y las ciencias. Bogotá, Universidad Nacional de Colombia, 1986.

HOYOS VÁSQUEZ, Guillermo. "Ética discursiva, derecho y democracia". En: Análisis político. Bogotá, Universidad Nacional de Colombia. (20) 93; págs. 5-19.

HUSSERL, Edmund. Lógica formal y lógica trascendental. México, FCE, 1962.

HUSSERL, Edmund. Cartesianische Meditationen. (Hua. I). Dordrecht, Martinus Nijhoff Publishers, 1973.

KANT, Inmanuel. Crítica de la razón práctica. Buenos Aires, Ed. Losada, 1973.

LEÓN XIII. Epístola encíclica Aeterni Patris. Sobre la restauración de la filosofía cristiana, conforme a la Doctrina de Santo Tomás de Aquino. 4 de agosto de 1879. http://www.filosofia.org/mfa/far879a.htm.

LLANO, Alfonso. "'Papá: ¿Qué es Semana Santa?" En: El Tiempo. Bogotá, 13 de abril 13.

LYOTARD, Jean-François. Los derechos del otro. En: http://www.geocities.com/maria patricia ochoa/otro.html.

MACINTYRE, Alasdair. Tras la virtud. Barcelona, Ed. Crítica, 1987. 
MACINTYRE, Alasdair. Tres versiones rivales de la ética. Enciclopedia, Genealogía y Tradición. Madrid, Ed. Rialp, 1996.

MISIÓN DE CIENCIA, EDUCACIÓN Y DESARROLLO. Colombia: al filo de la oportunidad. Informe conjunto. Bogotá, Presidencia de la República, 1994.

MOTTA, Cristina (Comp.). Ética y conflicto. Lecturas para una transición democrática. Bogotá, Tercer Mundo y Uniandes, 1994.

MUGUERZA, Javier. Desde la perplejidad. Ensayos sobre la ética, la razón y el diálogo. Madrid. FCE, 1996.

MUGUERZA, Javier y OTROS. El fundamento de los derechos humanos. Madrid, Ed. Debate, 1989.

NIETZSCHE, Friedrich. Zur Genealogie der Moral, Eine Streitschrift. Leipzig, Verlag von CG Naumann, 1887.

POPPER, Karl R. La lógica de la investigación científica. Madrid, Editorial Tecnos, 1977.

PUIG, Josep Ma. y MARTíNEZ, Miquel. Educación moral y democracia. Barcelona, Editorial Alertes, 1989.

RAWLS, John. Teoría de la justicia. México, FCE, 1978.

RAWLS, John. Sobre las libertades. Barcelona, Ed. Paidós, 1991.

RAWLS, John. Political Liberalism. New York, Columbia University Press, 1993.

RORTY, Richard. "La prionidad de la democracia sobre la filosofía". En: Vattimo, Gianni (Comp.). La secularización de la filosofía. Barcelona, Ed. Gedisa, 1992; págs. 31-61.

RORTY, Richard. Ironía, contingencia y solidaridad. Barcelona, Ed. Paidós, 1991.

SOBREVILLA, David. "El programa de fundamentación de una ética discursiva de Jürgen Habemas". En: Ideas y Valores. (74-75) 87; págs. 99-117.

STRAWSON, Peter. Freedom and Resentement and other Essays. London, Methuen, 1974.

TAYLOR, Charles. La ética de la autenticidad. Barcelona, Ed. Paidós, 1994.

THIEBAUT, Carlos. Los límites de la comunidad. Madrid, Centro de Estudios Constitucionales, 1992. 
TUGENDHAT, Ernesto. "El papel de la identidad en la constitución de la moralidad". En: Ideas y Valores. Bogotá, Universidad Nacional de Colombia. (8384) 90; págs . 3-14.

WALZER, Michael. "La idea de sociedad civil". En: Ciencia Política. Bogotá, Tierra Firme, II Trimestre. (35), 94; págs. 47-68. 